\title{
An Investigation of Theory and Its Application in Investment Management Education-Case of Pakistan
}

\author{
Naveed Iqbal (Corresponding author) \\ PhD Scholar, University of Bedfordshire, UK \\ Lecturer, University of the Punjab Gujranwala Campus Gujranwala, Pakistan \\ E-mail: naveediqbal81@yahoo.com
}

Searat Ali

MS Scholar, Management Science, Iqra University, Pakistan

E-mail: Captainsearat@hotmail.com

Kashif-ur-rehman

Associate Professor, Management Science, Iqra University, Pakistan

E-mail: drkashif@iqraisb.edu.pk

Mehmood Shah

Associate Professor, University of Management Science, Lahore, Pakistan

E-mail: mmshahkhan@hotmail.com

Zeeshan Akbar

MS Scholar, Management Science, Iqra University, Pakistan

E-mail: zeeshanakbar@yahoo.com

\begin{abstract}
Deviation of theory from practice is the burning question of the present age. As, numerous efforts have been commenced in multi programs to inspect this prevailing disparity between knowledge and practice at different venues. This study also aims to investigate the theory practice variation in the context of investment management education on the territory of Pakistan-what is taught by the investment academics in the universities to what is used by the investment professionals in the market. The data was collected from the sample of 30 investment academics and 23 investment professionals by using convenience non probability sampling technique. The sample size was reasonable as per the busy nature of respondents, time and cost constraints. Independent sample T-test was applied on the collected data in SPSS to measure the significant difference in the rating of both groups. The results revealed that there is a widening rift in the realm of investment management education. Out of 21 areas, the significant difference is found in 17 areas. Furthermore, in the light of results it is better to call Investment academics as fundamentalist and investment professionals as technician. Thus, noteworthy suggestion to Investment academics is that they must wake up and realize that investment is no longer solely driven by fundamental analysis.
\end{abstract}

Keywords: Fundamental, Technical analysis, Investment management education, Gap analysis

\section{Introduction}

The knowledge management has become progressively more important over the last few years. For gaining a competitive advantage Knowledge has become the key resource (Drucker, 1992). It is argued that theory without practice is fruitless and practice without theory is rootless (Hussain, 2004). If the tertiary education system is viewed as comprising knowledge enterprises (universities) that have many knowledge workers (academics) that endeavor to satisfy the needs of its clients (professionals) by providing knowledge products (graduates), it is 
essential to examine the gaps that may prevail between the importance of specific elements of the knowledge that is delivered and the knowledge that is required (Wolmarans, 2005).

In Pakistan, there seems to be a tug of war between academicians and professionals. The professionals are not happy with the set of courses being taught in universities, and about the lack of appropriate career counseling to students which would push them to have a more stabilized career. The academician blames the professionals for not coming forward to contribute in teaching as it is being done in developed countries. They also blame that the lack of industry support in providing internships is the hurdle in the path of students to be ready to face the real world challenges from the day of education (ILyas, 2009). In the field of investment management, it is observed that most of the academicians are teaching fundamental analysis whereas professionals are using technical analysis on the market mostly. It is the interesting fact that most of the academicians are aware about the extensive usage of technical analysis in the market but still they are not giving much time to technical analysis. They are of the view that fundamental analysis is better in predicting future while research has proved that technical analysis can be used for gaining superior returns (Sehgal \& Gupta, 2005). Furthermore empirical literature suggests that technical analysis is portable and can be used along with fundamental analysis (Kahn, 2006). The knowledge of the academician is tested with the help of different terms of technical analysis being used in the market by the professionals and it is found that academics are ignorant about those terms. So, there is a possibility that they are focusing on fundamental analysis due to lack of sufficient knowledge in technical analysis. The Text books and course outline were also being analyzed. It is concluded that more than $90 \%$ of the books and course outlines revolves around fundamental analysis whereas only $10 \%$ or less contains technical analysis. The text books which are recommended to the students are written by foreigners according to the scenario of foreign markets. So these text books do not cover the $100 \%$ practices of our local market. Different local terms are being used in the market like "kundi" "Bhatta" "Badla" "Gola" "lay Maal and day Maal". The concepts are available in the books but are with different terms. Theoretically it looks like a wide gap in investment management education and practices in Pakistan but it's too early to pass any final verdict until it is empirically proven.

So, This study attempts to investigate empirically that to what extent do the education provided to the students by investment management academics in the universities varies from practices of the brokers and dealers in the stock market with reference to the items of fundamental and technical analysis. The results of this study could be of value to different role players. Anyone who has even superficial concern in investment would be interested to know which areas have been mostly used by practioners and academics. If there are significant differences between the ratings of practitioners and the ratings of academics of various areas in investment, the differences could be of value to both these groups. Academics could be able to construct balanced course outline for better future training of students and practitioners could know where inputs should be made if future academic training is to resolve the problems that they face. Higher education commission of Pakistan could too use the findings to improve the quality of investment management education by taking appropriate actions. Without knowing how much gap is prevailing it is not possible to take an appropriate amount of remedial action. This study will measure the gap and hence guide the authorities for taking the appropriate amount of remedial action. Higher the gap higher will be the action and vice versa.

Remainder of the study is organized as follows. Next section discusses review of the literature. The third section demonstrates methodology employed in this study. The fourth section deals with results and discussion. Finally, section 05 concludes by providing some implications and recommendations for future research.

\section{Literature review}

Theory practice gap has been investigated in different countries in various fields and the academics are often accused of "living in an ivory tower" by the professionals and not focusing on the needs of the practitioners when educating students in various programs (Wolmarans, 2001). This argument is further strengthened as Sun et al. (2007) in Japan too found wide 'perception gap' between industries and universities. Similarly, in Turkey it seemed to be an amplifying gap between what labor markets required and what education institutes are producing. So, this gap has developed a strong perception among the professionals that newly trained people (students) who come from the education sector do not have sufficient and up-to-dated knowledge (Standard Summary Project Fiche, 2006). However, Lee et al. (2002) examined the gap between the academics and practitioners of information system and found no consensus about which skills are more important in information system profession. Similarly, Trauth et al. (1993) studied the expectation gap in information system. Whereas Hawkes et al. (2003) investigated perception gap between academics and practitioners in management accounting education and found significant gap. Moscardo and Norris (2005) have made an effort to bridge academic practitioner gap in event management by training students with market oriented assignments. As 
Brennan (2008) debated on the solutions of theory practice gap across the disciplines of economics, nursing and marketing.

The financial and investment education literature too often contains a discussion on what is considered to be an appropriate balance between theory and practice to assure the relevance in the program. Among these efforts, Smith and Goudzwaard (1970) reviewed and found widening rift between practitioners and academicians in investment management education. The gap was due to rapid changes in academia and practices, non acceptance of advance theories by the practitioners and Unsuccessfulness of applying some theories in the market. They suggested that curricula must be re-evaluated on a consistent basis to fill the gap. Eiteman \& Smith (1974) evaluated the portfolio mix of investment subject and identified five thrusts of investment subject which has dominated the curricula, research and text books since 1920. These thrusts were fundamental analysis, institutional orientation, capital market theory, technical analysis and portfolio theory. They concluded that technical analysis was accepted in the start by the academician but with the passage of time the acceptance level seemed to diminish. The portfolio theory remained consistent throughout its life. Capital market theory was getting increased coverage since its origination. Institutional orientation got extensive position in the start but decreased later on. Fundamental analysis also decreased in the text books but still it covers the maximum part of the portfolio mix of the investment subject. Whereas Weaver, (1993) used an analogy of frogs to emphasize that academics should work with the practitioner to structure issues in a way that bridges the widening gap between financial theory and practice.

Few years later, Wolmarans (1999) investigated the existence of such a gap in the field of financial management. He concluded that the role of finance in the firm, income statement, balance sheet, mergers and acquisition, and foreign exchange rate were considered significantly important topics by the practitioners than the academics. Whereas, capital budgeting techniques, Short term and medium term financing, cash and marketable securities were considered significantly important topics by academics than the practitioners. By putting in another way, Wolmarans (2001) again examined theory practice gap in the area of investment management by using 26 topics. Both practitioners and professors of finance had been asked to rank those areas according to their perceived importance. He found amplified rift in most of the topics. Lo et al. (2000) proved the viability of technical analysis that it can add value to the process of investment; he argued that one of the greatest gaps between finance academics and practitioners is the separation that prevails between technical analysts and their academic critics. In opposite to fundamental analysis, which was quickly adopted by the academics of modern quantitative finance, technical analysis, due to its subjective nature, has been an orphan from the days of its origin. So, Boulier (2003) calls for fruitful contacts between finance academics and professionals for transforming new researches into useful practices and thus eliminating the prevailing gap. As Chang (2005) stated that rapidly changing environment has decreased the usefulness of class room taught financial theories. So, there is a need for reviewing which financial theories should be taught in universities and how in order to bridge the gap between theory and practice.The study of Flanegin \& Rudd (2005) confirmed the argument of lo et al., (2000) and measured the gap between professors and practitioners of investment management with reference to fundamental and technical analysis. The results showed that professors mostly teach fundamental analysis in the class room whereas; practitioners use technical analysis mostly in the workplace. Thus, disparity exists between investment education and practice. However, Bettman et al. (2009) empirically proved that technical and fundamental analysis are not substitutes rather both are complementary to each other and must be used together. So, investment professors must wake up and realize the complementary nature of fundamental and technical analysis. More Recently, Lyons and Neelakantan (2008) argued that practitioners do not consider theory as valuable because it does not describe how people behave in the real world. They suggested that Better communication can fill the theory practice gap for the benefit of the consumer. Similarly, Siegel (2008) argued that there is a gap between studying to be an advisor and being one. So, more communication is needed between academics and practitioners.

To sum up, the review of literature explicitly stated the existence of gap between knowledge and practice in investment management around the globe. Since, no study found which measured the theory practice gap in investment management education of Pakistan. The present study would be a contribution to the existing literature of investment management education specifically in Pakistan (see figure.1 for theoretical fame work).

\section{A. Hypotheses to be tested}

In the light of the problem statement and literature review following hypotheses were e tested to address the stated problem. 
Hypothesis No 01: There is no difference between what is taught by the academics and to what is used by the professionals.

Hypothesis No 02: The areas that academics teach mostly in investment subject are the same as the areas that professionals use mostly in the market.

Hypothesis No 03: The areas that academics teach less in investment subject are the same as the areas that professionals use less.

Hypothesis No 04: Both academics and professionals are equally aware about the level of university industry collaboration.

\section{Methodology}

There were two groups in the survey; 30 Investment academics and 23 investment professionals (brokers and dealers) participated in the survey. To select this sample, non-probability convenience sampling had been used. The small sample size of academics was constrained by the non availability of data base which could provide the detail about investment academics and investment professionals. The time and cost constraints were also the reasons of small sample size. List of universities had been acquired from the website of Higher education commission of Pakistan where as the addresses and contact numbers of the universities were taken from hamariweb.com. Then calls have been made to the professionals who are engaged in teaching of subject of investment management for seeking their cooperation and building interpersonal relationship. Similarly, Sample of Professionals (brokers and dealers) had been acquired from the websites of Islamabad, Lahore and Karachi stock exchanges. Then the calls have been made to professionals and interpersonal relationship has been developed.

In compiling a questionnaire for this study, the general makeup of the area that Flanegin \& Rudd (2005) complied, was adopted as a point of departure. The list of areas to be included was adjusted after various interviews from the experts of investment management education. It was decided to utilize questionnaire rather than to commence telephonic interviews, because of busy nature of respondents and this method would facilitate them to complete and return the questionnaire at their ease. The questionnaire has been divided into two parts. The first part was the addition in the pre established scale and contained four questions. These questions were related to see the general level of perception of both groups about importance of education, training in universities, communication channel and gap in investment management education. Investment academics and professionals has been asked to specify their level of agreement or disagreement ranging from 1 strongly disagree to 5 strongly agree on four questions. The second part of the questionnaire contained the areas of fundamental and technical analysis. Various recommended investment text books in the universities and several interviews with academics and professionals have been used to determine the items of fundamental and technical analysis in the questionnaire as per the local scenario. The twenty one items ( 09 fundamental and 12 technical) has been ranked by the investment academics on a one to five scale, one spending very little time in class on the item to five spending considerable time. The same twenty items ( 09 fundamental and 12 technical) has been ranked by investments academicians on a one to five scale, with one signifying the subject was very rarely utilized within the realm of their job to five; the subject material was utilized within the realm of their job on a fairly consistent basis.

Most of the survey questionnaire has been self-administered and distributed personally among respondents. Before giving the questionnaires, concise introduction about the research idea has given with an ambition to obtain relevant data. The survey was cross sectional and, data was obtained from the respondents once. Total questionnaire distributed to both groups was eighty (forty to each). From forty questionnaires to academics, 36 questionnaires were retrieved. Six were not properly filled and thus eliminated from the sample. The proper response rate was $75 \%$. Out of forty questionnaires to professionals, 26 were retrieved. Three were not in good condition and thus extracted from the sample. The proper response rate was $57.5 \%$. SPSS has been used to analyze the data of both groups. As the study was to measure the difference between the two groups so, independent sample T-test has been applied on the data to investigate the mean differences in the rating of both groups. The level of significance taken was $5 \%$. If the significant 2 -tailed value is less than 0.05 , it means that there is a significant difference between the rating of academics and professionals. If the significant 2-tailed value is greater than 0.05 , it means that there is no significant difference between the rating of academics and professionals.

\section{Results and Discussions}

Hypothesis one states that there is no difference between what is taught by the academics and to what is used by the professionals. Table 01 (see appendix) presents the results of the rating given by the two groups in the survey. 
The results are shown in the form of means and standard deviations of academics and professionals, the mean difference, significant two tailed value and T-value. It is evident from the table that mean rating differ significantly for 17 areas out of 21 . The areas that professionals significantly use more than the academics teach are volume tracking, trading ranges, trend lines, crowd psychology, types of charts, relative strength index, advance decline issues, support resistance levels, MACD and simple moving averages. The managerial implication behind these findings is that these areas should be given more time in teaching investment management subject. However, the areas that academics significantly teach more than the professionals use are Portfolio Theory, Efficient Market Hypothesis, Dividend Discount Model, Required Rate of Return, Arbitrage Pricing Theory, Capital asset pricing model and E-I-C Analysis or C-I-E. These results reveals that academics are inclined towards fundamental analysis where as professionals are inclined towards technical analysis. It is somewhat surprising that there are only 4 areas out of 23 on which both groups are united. These areas are ratio analysis, relative valuation techniques, absolute breadth index and stochastic. The ratio analysis and relative valuation techniques are universally accepted as mean is above 4 for both groups whereas absolute breadth index and stochastic is universally rejected as mean is below 2.5 for both groups. These results depicts that that there are various areas in which there is highly significant difference between the rating of professionals and academics so hypothesis one is rejected.

Hypothesis two states that the areas that academics teach mostly in investment subject are the same as the areas that professionals use mostly in the market. Table 02 (see appendix) presents the five areas rated at top by academics and professionals with respect to mean. In the five highly rated areas of both groups there is only one overlapping area that is ratio analysis. Whereas other four areas are different for both groups, which indicates that the areas that academics teach mostly in investment subject are not the same as the areas that professionals use mostly in the market. So, Hypothesis two is also rejected. Furthermore, table demonstrates that all the five areas which the academics rated high are related to fundamental analysis which shows that the major focus of academics is on fundamental analysis however two out of five items rated high by professionals are related to fundamental analysis whereas the remaining three are related to technical analysis. So, major focus of professionals is on technical analysis.

Hypothesis three states that the areas that academics teach less in investment subject are the same as the areas that professionals use less in the market. Table 03 (see appendix) presents the five areas rated low by academics and professionals with respect to mean. In the five low rated areas of both groups there is only one overlapping area that is absolute breadth index. Whereas other four areas are different for both groups, which indicates that the areas academics teach less in investment subject are not the same areas that professionals use less in the market. So, Hypothesis three is also rejected. Additionally, in the above table it is found that, all the five low rated areas by the academics are related to technical analysis which shows that academics dislike technical analysis. However, out of five areas rated low by professionals' only one area is concerned with technical analysis. This indicates that professionals rarely use fundamental analysis in the market.

Hypothesis four states that both academics and professionals are equally aware about the level of university industry collaboration. To test this hypothesis four questions were asked. The results are shown in table 04 (see appendix) in the form of means of groups, mean differences and significance (2-tailed). The first question was "Academic education is necessary to be a good practitioner in market". The mean of both groups is 4 (agree), mean difference is -0.01159 and significant 2-tailed value is 0.961 which shows; both groups are equally emphasizing on the importance of education in the market. The Second question was "Professionals believe that academics aren't training students according to market". The mean of both groups is 3.86 , mean difference is -0.0029 and significant 2 -tailed value is 0.989 which shows that both groups are agreed on the statement. The professionals believe that academics are not training students according to market and academics are aware about this believes of professionals. The third question was "is there proper channel of communication between Academics and Professionals?" The mean of both groups is near to 2, mean difference is 0.1 and significant 2 -tailed value is 0.708 which shows that both groups are equally disagreeing on the statements, in other words both groups believe that there is no communication between academics and professionals. The fourth question was "In Pakistan Investment management education is well matched with practice". The mean of both groups is near to 2.3, mean difference is 0.908 and significant 2-tailed value is 0.708 which shows that both groups are equally disagreeing on the statement which means that the investment management education is not well matched with practice. The discussion about the four statements revealed that both the academics and professionals are equally aware about the level of university industry collaboration. So, hypothesis four is accepted. This opens the new avenue for researchers that both groups are equally aware about the gap between 
industry and universities but yet neither professionals nor academics are coming up with the solution to bridge the gap.

\section{Conclusion and Recommendations}

Just like market has its bulls and bears, investing has its academics and professionals. This paper revealed that there is a widening gap between what is taught to what is used in the market in the field of investment management. The core concern of academics is on fundamental analysis whereas the professionals are relying on technical analysis in the realm of market. In other words Current Investments courses are giving students only a partial foundation of investments knowledge on which to build their careers. So, it is recommended to academics that they should also focus on technical analysis along with fundamental analysis. Because technical and fundamental analysis is not substitute rather both are complementary to each other (Bettman et al., 2009). The course outline of investment subject should include the contents of technical analysis. The recommendation to Higher Education Commission of Pakistan is to consider the issue and make remedial actions to bridge this widening gap. The recommendation for professionals is to come up in the universities and deliver their experiences so the disparity can be resolved. This study only identified the gap in investment management but yet the reasons for the gap are undecided. So, the potential area for future research is to investigate the reasons for the widening gap in investment management education. There can be plenty of reasons one of those may be that only one course is offered in universities related to investment management, so it may be difficult to cover all the areas of fundamental and technical analysis. The study ignored the demographic variables as well, so the second avenue for future research is to measure the gap with respect to demographic variables like location, gender, public or private University etc.

\section{References}

Bettman, J.L, Sault, S.J and Schultz, E.L. (2009). Fundamental and technical analysis: substitutes or complements? Accounting and Finance, Vol. 49, pp. 21-36.

Boulier, J.F. (2003). Bridge the gap: fruitful contacts between finance professionals and Academics are needed. International journal of business, Vol. 8(4).

Brennan, R. (2008). Theory and practice across disciplines: implications for the field of management. European Business Review, Vol. 20 No. 6, pp. 515-528.

Chang, S.J. (2005). A Theoretical Discussion on Financial Theory: What Should We Teach and How? Journal of economics and finance education, Vol. 04, pp. 39-48.

Drucker, P.E. (1992). The new society of organizations. Harvard Business Review, Vol. 70, pp.95-104.

Eiteman, D.K., and Smith, K.V. (1974) A Portfolio Analysis of the Teaching of Investments. The Journal of Financial and Quantitative Analysis, Vol. 09, No. 5, pp. 771-780.

Flanegin, F.R and Rudd, D.P. (2005). Should Investments Professors Join the Crowd?. Managerial Finance, Vol. 31, pp. 28-37.

Hawkes, L.C., Fowler, M., and Tan, L.M. (2003). Management accounting education: Is there a gap between academia and practitioner perception?. School of accountancy, Discussion paper series 215.

Hussain, K. (2004). Introduction to logic-deductive logic ( $1^{\text {st }}$ ed.). Pakistan, Azeem Academy Publishers.

ILyas, S. (2009, April 22). Retrieved May 23, 2009, from STEP.

Jensen, M.C., and Benington, G.A. (1970). Random Walks and Technical Theories: Some Additional Evidence. Journal of Finance, Vol. 25, pp. 469-482.

Kahn, M.N. (2006). Technical analysis Plain and simple: Charting the market in your language (2nd ed.). United states of America, New Jersey: Pearson Education

Lee, S., Koh, S., Yen, D., and Tang, H. (2002). Perception gaps between IS academics and IS practitioners: an exploratory study. Information and management, Vol. 40, issue 01, pp. 51-61.

Lo, A.W., Mamaysky, H., and Wang, J. (2000). Foundations of Technical Analysis: Computational Algorithms, Statistical Inference, and Empirical Implementation. The journal of finance, Vol. No. 04, pp. 1705-1765.

Lyons, A.C., and Neelakantan, U. (2008). Potential and Pitfalls of Applying Theory to the Practice of Financial Education. The journal of consumer affairs, Vol. 42, pp. 106-112

Moscardo, G., and Norris, A. (2005). Bridging the Academic Practitioner Gap in Conference and Events Management: Running Events with Students. Journal of Convention \& Event Tourism, Vol. 6(3), pp. 47-62. 
Reilly, F., and Brown, K. (2006). Investment analysis and portfolio management ( $8^{\text {th }}$ ed.). India: Thomson Learning inc.

Siegel, A. (2008). A gap between studying to be an advisor and being one

Smith, K.V, and Goudzwaard, M.B. (1970). Survey of Investment Management: Teaching versus Practice. The Journal of Finance, Vol. 25, No. 2, pp. 329-347.

Standard Summary Project Fiche. (2006). Instrument of financial support to encourage the economic development of the Turkish Cypriot community.

Sun, Y., Negishi, M., and Nishizawa, M. (2007). Coauthorship linkages between universities and industry in Japan. Research evaluation, Vol. 16, pp. 299-309.

Trauth, E.M., Farwell, D.W., and Lee, D. (1993). The IS Expectation Gap: Industry Expectations versus Academic Preparation. MIS Quarterly, Vol. 17, No. 3, pp. 293-307.

Weaver, S.C. (1993). Why Don't We Just Ask Them?. Financial practice and education, pp. 11-13

Wolmarans, HP. (1999). Financial management education: Is there a gap between the academics and of practitioners?. South African Journal of management and economic science, (New series) Vol. 02, No. 03, pp. 523-535.

Wolmarans, HP. (2001). Investment management education: Is there a gap between the perceptions of academics and of practitioners?. Meditari Accountancy Research, Vol. 9, pp. 351-366.

APPENDIX No. 01

Table 1. Results of independent sample t-test for all the areas of both groups

\begin{tabular}{|l|l|l|l|l|l|l|l|}
\hline \multirow{2}{*}{ Items } & \multicolumn{2}{|c|}{ Academics } & \multicolumn{2}{c|}{ Professional } & \multicolumn{1}{l}{$\begin{array}{l}\text { Sean } \\
\text { Dif }\end{array}$} & $\begin{array}{l}\text { Sig. } \\
(2- \\
\text { tailed) }\end{array}$ & T- Value \\
\cline { 2 - 7 } & Mean & SD & Mean & SD & & & \\
\hline Stochastic* & 2.2 & 1.18613 & 2.2609 & 1.00983 & -0.06087 & 0.844 & -0.197 \\
\hline Portfolio Theory & 4.5333 & 0.50742 & 1.5217 & 0.59311 & -0.06087 & 0 & -0.202 \\
\hline Volume tracking* & 2.4667 & 0.81931 & 3.6087 & 0.72232 & -1.14200 & 0 & 19.9 \\
\hline Ratio Analysis & 4.4333 & 0.8172 & 4.3478 & 1.07063 & 3.01159 & 0.743 & 19.49 \\
\hline Trading ranges* & 2.5 & 1.00858 & 3.7826 & 0.95139 & -1.14203 & 0 & -5.29 \\
\hline Crowd psychology* & 1.8667 & 1.10589 & 3.913 & 1.27611 & -1.14203 & 0 & -5.38 \\
\hline EMH & 4.3333 & 1.06134 & 1.913 & 1.23998 & 0.08551 & 0 & 0.33 \\
\hline Trend lines* & 2.8667 & 1.07425 & 3.6957 & 0.76484 & 0.08551 & 0.003 & 0.318 \\
\hline Dividend Discount Model & 4.3333 & 0.71116 & 3.4348 & 1.12112 & -1.28261 & 0.001 & -4.702 \\
\hline Types of Charts* & 2.8333 & 1.41624 & 3.7391 & 0.91539 & -1.28261 & 0.01 & -4.739 \\
\hline Absolute breadth index* & 1.6 & 1.06997 & 1.7826 & 1.1264 & -2.04638 & 0.55 & -6.245 \\
\hline Required Rate of Return & 4.2667 & 0.98027 & 1.9565 & 1.06508 & -2.04638 & 0 & -6.127 \\
\hline Relative Strength Index * & 2.7333 & 1.28475 & 3.5652 & 0.99206 & 2.42029 & 0.013 & 7.648 \\
\hline Arbitrage Pricing Theory & 3.8333 & 1.05318 & 1.8696 & 0.86887 & 2.42029 & 0 & 7.491 \\
\hline Advance decline issues* & 2.7 & 1.20773 & 3.5217 & 0.94722 & -0.82899 & 0.01 & -3.138 \\
\hline CAPM & 4.3 & 1.02217 & 1.8261 & 0.88688 & -0.82899 & 0 & -3.279 \\
\hline Support \& resistance leve** & 2.5 & 1.16708 & 3.6957 & 1.06322 & 0.89855 & 0 & 3.559 \\
\hline Relative valuation Tech. & 4.1 & 0.88474 & 3.9565 & 0.87792 & 0.89855 & 0.56 & 3.36 \\
\hline MACD* & 2.2 & 1.18613 & 3.8261 & 1.11405 & -0.9058 & 0 & -2.667 \\
\hline E-I-C Analysis or C-I-E & 3.3 & 1.14921 & 2.3478 & 0.93462 & -0.9058 & 0.002 & -2.818 \\
\hline Simple moving averages* & 2.6667 & 1.06134 & 3.913 & 0.90015 & -0.18261 & 0 & -0.602 \\
\hline
\end{tabular}

Note: Items with * indicates the areas of technical analysis 
Table 2. Five high areas by both groups

\begin{tabular}{|l|l|l|l|}
\hline \multicolumn{2}{|l|}{ Five high rated areas-Academics } & Five high rated-professionals & Mean \\
\hline Areas & Mean & Areas & 4.347 \\
\hline Portfolio theory & 4.53 & Ratio Analysis & 3.965 \\
\hline Ratio Analysis & 4.43 & Relative valuation technique & 3.913 \\
\hline EMH & 4.33 & Crowd Psychology & 3.910 \\
\hline DDM & 4.33 & Simple moving averages & 3.826 \\
\hline CAMP & 4.30 & MACD & \\
\hline
\end{tabular}

Table 3. Five low rated areas by both groups

\begin{tabular}{|l|l|l|l|}
\hline \multicolumn{2}{|l|}{ Five Low rated areas-academics } & \multicolumn{2}{l|}{ Five Low rated areas-professionals } \\
\hline Areas & Mean & Areas & Mean \\
\hline Absolute breadth index & 1.60 & Portfolio theory & 1.521 \\
\hline Crowd Psychology & 1.866 & Absolute breadth index & 1.782 \\
\hline MACD & 2.21 & CAPM & 1.826 \\
\hline Stochastic & 2.20 & APT & 1.869 \\
\hline Vloume Tracking & 2.466 & EMH & 1.913 \\
\hline
\end{tabular}

Table 4. Results for hypothesis 04

\begin{tabular}{|c|c|c|c|c|}
\hline Statements & $\begin{array}{l}\text { 'A' } \\
\text { mean }\end{array}$ & $\begin{array}{l}\text { ' } \mathrm{P} \text { ' } \\
\text { means }\end{array}$ & Mean Diff. & $\begin{array}{l}\text { Sig. } \\
\text { (2-tailed) }\end{array}$ \\
\hline $\begin{array}{l}\text { 1-Academic education is necessary to be a good } \\
\text { practitioner in market }\end{array}$ & 4.4667 & 4.6087 & -0.01159 & 0.961 \\
\hline $\begin{array}{l}\text { 2-Professionals believe that academics aren't } \\
\text { training students according to market }\end{array}$ & 3.8667 & 3.8696 & -0.0029 & 0.989 \\
\hline $\begin{array}{l}\text { 3-There is proper channel of communication } \\
\text { between Academics and Professionals }\end{array}$ & 2.1 & 2 & 0.1 & 0.708 \\
\hline $\begin{array}{l}\text { 4-In Pakistan Investment management education } \\
\text { is well matched with practice }\end{array}$ & 2.3333 & 2.3043 & 0.02899 & 0.908 \\
\hline
\end{tabular}

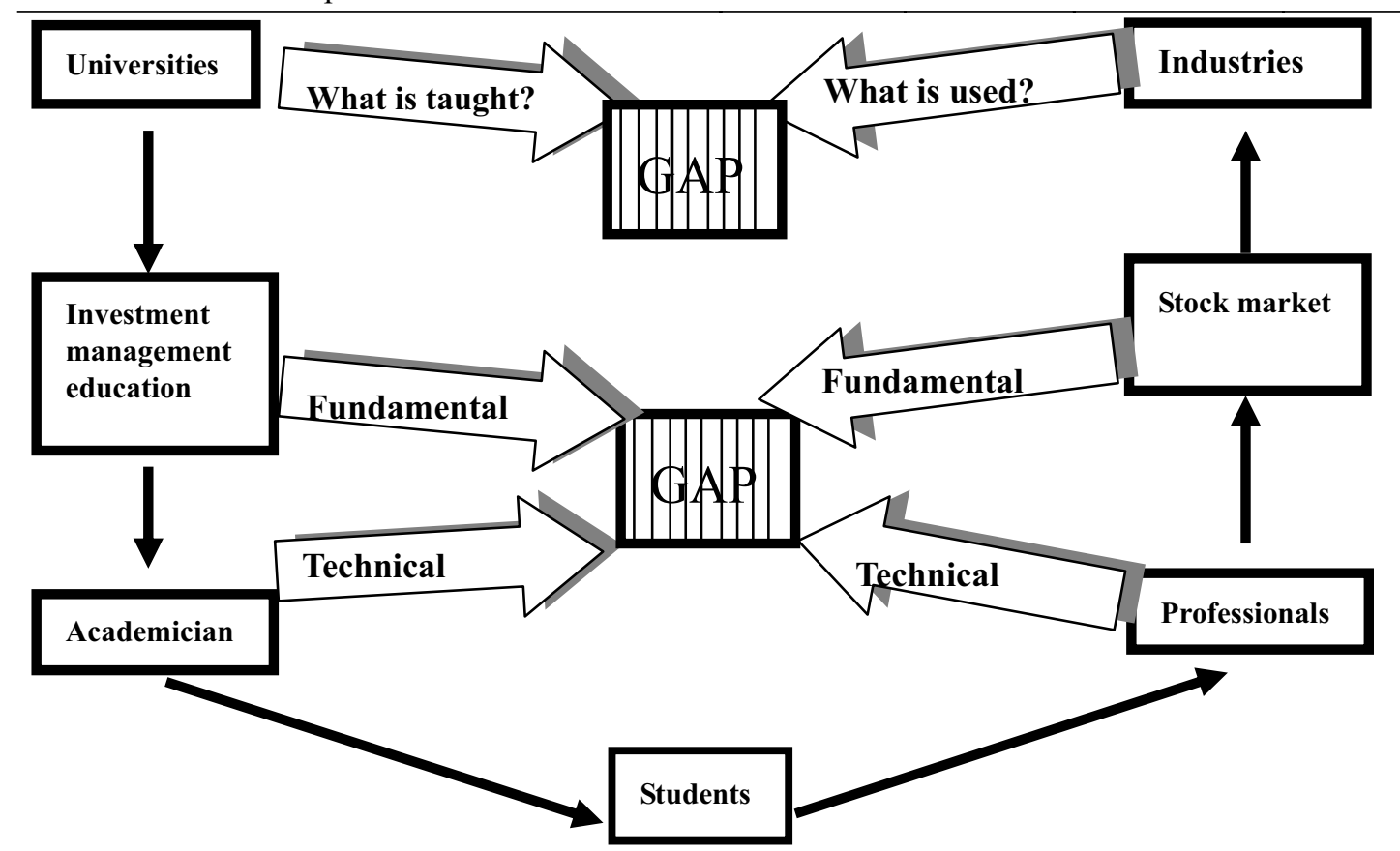

Figure 1. Theoretical Framework 
QUESTIONNAIRE

Please rate the statements 1-4 as follows

\begin{tabular}{|l|l|l|l|l|}
\hline 1- Strongly Disagree & 2- Disagree & 3- Not Decided & 4- Agree & 5- Strongly Agree \\
\hline
\end{tabular}

\begin{tabular}{|ll|l|l|l|l|l|}
\hline \multicolumn{3}{|c|}{ Statements } & \multicolumn{4}{|c|}{ Rating } \\
\hline 1. & Academic education is necessary to be a good practitioner in market & 1 & 2 & 3 & 4 & 5 \\
\hline 2. & Professionals believe that academics aren't training students according to market & 1 & 2 & 3 & 4 & 5 \\
\hline 3. & There is proper channel of communication between Academics and Professionals & 1 & 2 & 3 & 4 & 5 \\
\hline 4. & In Pakistan Investment management education is well matched with practice & 1 & 2 & 3 & 4 & 5 \\
\hline
\end{tabular}

Please rate the Items 5-25 as follows

\begin{tabular}{|l|l|l|l|l|}
\hline 1- Do not teach & 2- Teach a little & 3- Teach a moderate amount & 4- Teach a Lot & 5- Teach all the time \\
\hline
\end{tabular}

\begin{tabular}{|l|l|l|l|l|l|}
\hline \multicolumn{2}{|c|}{ Items } & \multicolumn{5}{|c|}{ Rating } \\
\hline 5. Stochastic & 1 & 2 & 3 & 4 & 5 \\
\hline 6. Portfolio Theory & 1 & 2 & 3 & 4 & 5 \\
\hline 7. Volume tracking & 1 & 2 & 3 & 4 & 5 \\
\hline 8. Ratio Analysis & 1 & 2 & 3 & 4 & 5 \\
\hline 9. Trading ranges & 1 & 2 & 3 & 4 & 5 \\
\hline 10. Crowd psychology & 1 & 2 & 3 & 4 & 5 \\
\hline 11. Efficient Market Hypothesis & 1 & 2 & 3 & 4 & 5 \\
\hline 12. Trend lines and its implications & 1 & 2 & 3 & 4 & 5 \\
\hline 13. Dividend Discount Model & 1 & 2 & 3 & 4 & 5 \\
\hline 14. Types of Charts and its reading & 1 & 2 & 3 & 4 & 5 \\
\hline 15. Absolute breadth index & 1 & 2 & 3 & 4 & 5 \\
\hline 16. Required Rate of Return & 1 & 2 & 3 & 4 & 5 \\
\hline 17. Relative Strength Index & 1 & 2 & 3 & 4 & 5 \\
\hline 18. Arbitrage Pricing Theory & 1 & 2 & 3 & 4 & 5 \\
\hline 19. Advance decline issues, ratios and line & 1 & 2 & 3 & 4 & 5 \\
\hline 20. Capital asset pricing model (CAPM/ Beta) & 1 & 2 & 3 & 4 & 5 \\
\hline 21. Support and resistance levels (S1,S2 and R1,R2) & 1 & 2 & 3 & 4 & 5 \\
\hline 22. Relative valuation techniques (P/E, P/B, P/C) & 1 & 2 & 3 & 4 & 5 \\
\hline 23. Moving Average Convergence and Divergence (MACD) & 1 & 2 & 3 & 4 & 5 \\
\hline 24. E-I-C Analysis or C-I-E (Top down approach or Bottom up) & 1 & 2 & 3 & 4 & 5 \\
\hline 25. Simple moving averages (15 days, 50 days 200 days) & 1 & 2 & 3 & 4 & 5 \\
\hline
\end{tabular}

